\title{
Ecopolis: Architecture and cities for a changing climate
}

Paul F Downton.

Springer and CSIRO Publishing. www.publish.csiro.au, 2009,

i-xix pages+ 1-607 pages, AUSS130, ISBN 9781402084959

Literature on cities and climate change/adaptation is becoming more prolific as we enter the second decade of the 2000s. This is perhaps not surprising given the alarming predictions and forecasts for cities, the ecology and life in general. In this context of anomalies and uncertainties Paul Downton's book is a welcome, optimistic and positive contribution. The book is about urban ecology and is intended as a core text for students, it is concerned with ways of thinking and ways of doing urban ecology. The stated goal of the book (p. vii) 'is to promote an understanding of cities as essential tools to the survival of advanced civilization.' This goal is a mammoth, ambitious and complex task to be achieved in a single volume, albeit 607 pages consisting mostly of small closely spaced text. The result is a comprehensive and somewhat shallow coverage of every aspect of urban ecology; from various histories and theoretical standpoints, to planning techniques and practices, to relationships between planning and architecture, to the importance of design and aesthetic considerations, to issues of gender, diversity and equity, to discussions on ecology and the relationships between living organism and the city, to name but a few of the topics covered.

This is a very long book and perhaps not one that is meant to be read from cover to cover sequentially from page 1 through to page 607. As a student text it will be best used as a sort of encyclopaedia of urban ecology; as a guide to the breadth and complexity of the subject. The student will however be obliged to follow up with additional research for a more detailed and in depth understanding of urban ecology.

When I was asked to review this book, I accepted with great anticipation. Paul Downton was an influential teacher and mentor during my studies for my architectural degree. He was a passionate and committed urban ecologist at a time when urban ecology was far from trendy, or even deemed important in architectural and planning education and or practice. This book demonstrates the depth and persistency of his aspirations and endeavours over the years. Indeed the book is an autobiography in many respects, drawing upon his personal experiences and projects he has been involved with. Down ton's life, it seems, has been lived through his passion for bringing architecture, planning and ecosystems together to produce his vision of Ecopolis; the city as an integral part of a healthy and viable ecosystem. In this sense, the book clearly shows the extent to which an individual (as an architect, planner, teacher and critic) can influence the dominant planning and architectural trends of the time.

To explain the significance of urban ecology and the making of an Eco polis, the book is divided into two sections, each of which consist of a series of sub-sections which in turn are broken down into a number of short discussion topics. This report-like structure is necessary given the breadth of the subject matter and the goal of the book. It seems at times that Downton is using the book as an excuse to demonstrate the extent of his knowledge, and a key to this may be a line included in the Summary (p. vii) which suggests that the content of the book is based upon the author's PhD thesis. 
Part one of the book focuses on architectural and planning theories, policies and projects, some of which have direct links to urban ecology and some of which are more tenuous, all be they important. In this section of the book, Downton argues the importance of history in understanding current urban patterns, and that 'we must understand how this phenomenon of building cities is central to our survival' (p. 20). Downton writes (p. 14) that the 'solution to our problem of city-making lies in the way we make cities, that we already have the necessary means and knowledge but we need a better sense of how the pieces all connect and must learn how to put it all together a little differently.' The eco-city case studies that conclude part one include Curitiba, Calcutta and Downton's own projects in Adelaide, South Australia. Indeed the final chapter in Part one is given over entirely to relating the history of Downton's practice, Eco polis Architects and the non-profit organisation he co-founded, Urban Ecology.

Part two of the book is perhaps the more interesting and pertinent. It draws upon some of the material in Part one, however Part one is not a prerequisite to understanding this final section. Part two is complete in itself and represents the core text for students of urban ecology. Downton's premise in constructing his concept of Ecopolis is that cultural change is imperative, and importantly, possible. This premise many would argue is utopian, given the histories and structures of society. Downton argues (p. 349) that the 'real task is not the making of buildings but the creation of an ecological culture'. And the means to create this culture is through education and the re-establishment of 'citizenship' as an ethical practice, also achieved through education. Downton uses the acronym SHED (Sustainable Human Ecological Development) as a framework to achieve cultural change and realise his Ecopolis. The explanation of SHED is interesting and inspiring, although sceptics will not be convinced that the required cultural change can be achieved. I believe Part two of the book is a key text that has the potential to awaken possibilities to do architecture and planning differently, in ways that are more aligned with eco-systems, and both mitigate and adapt to climate change.

The structure of the book is clear and logical and the section titles are unambiguous and relevant to the text that follows. The writing style is engaging and easy to read, although sometimes sweeping and biased, but then the author is an advocate of urban ecology and eco cities. Downton writes ( $p$. 57) 'architecture is to do with a self-referencing object-orientated craft activity-planning is to do with placing the objects of architecture in patterns which do not adversely affect the dominant economic order. Any connection between these activities and the state of the planet's ecological health ... [are] incidental or peripheral to the central task of architectural creativity or pragmatic planning.' Extracts like this, and there are many of them, may raise the hackles of some, especially those planners who work in fields that are far more than pragmatic and those architects whose work is far more than self-referential object making.

The book is well illustrated, as one might expect from an architect, with both photographs and illustrations drawn by Downton over the course of his career. The illustrations are well executed, if somewhat self-indulgent, and depict a history of ideas and illustration techniques rather than having an obvious relevance to the core message of the book.

In summary, this book is about the relation between architecture, planning and ecology as well as giving the reader an analysis, if sometimes shallow, of the parts of these mega discourses. The book 
does not cover the science of climate change and although neither the term 'climate adaptation' nor 'climate mitigation' is used by Downton, perhaps these terms best describe his Ecopolis project. Basically, Downton is arguing that people must live their everyday lives very differently and that cities must function very differently in ways that are ecological and integral to the health and well being of the planet and its biosphere. This for many will be a difficult pill to swallow, even with the known effects of climate change, and Downton is not holding back in his ardent pursuit of realising his vision of Ecopolis.

Caryl Bosman

Urban Research Program

Griffith University 